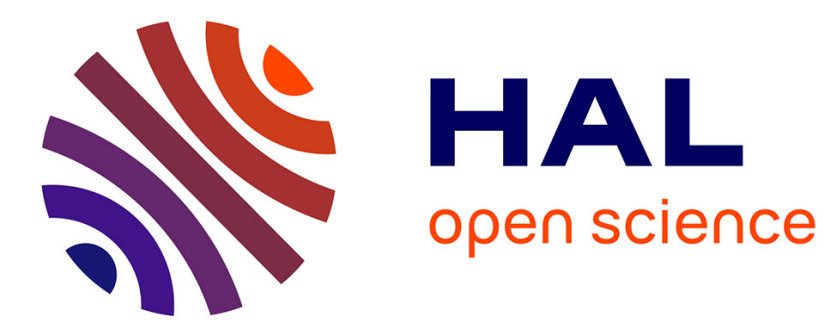

\title{
LOCAL MODEL OF MAGNETISM FOR Cu-Ni ALLOYS
}

B. Cornut, J. Perrier, B. Tissier, R. Tournier

\section{To cite this version:}

B. Cornut, J. Perrier, B. Tissier, R. Tournier. LOCAL MODEL OF MAGNETISM FOR Cu-Ni ALLOYS. Journal de Physique Colloques, 1971, 32 (C1), pp.C1-746-C1-747. 10.1051/jphyscol:19711258 . jpa-00214088

\section{HAL Id: jpa-00214088 https://hal.science/jpa-00214088}

Submitted on 1 Jan 1971

HAL is a multi-disciplinary open access archive for the deposit and dissemination of scientific research documents, whether they are published or not. The documents may come from teaching and research institutions in France or abroad, or from public or private research centers.
L'archive ouverte pluridisciplinaire HAL, est destinée au dépôt et à la diffusion de documents scientifiques de niveau recherche, publiés ou non, émanant des établissements d'enseignement et de recherche français ou étrangers, des laboratoires publics ou privés. 


\title{
LOCAL MODEL OF MAGNETISM FOR Cu-Ni ALLOYS
}

\author{
B. CORNUT, J. P. PERRIER, B. TISSIER, R. TOURNIER \\ Centre de Recherches sur les Très Basses Températures, \\ Centre National de la Recherche Scientifique, Cedex 166, \\ 38, Grenoble-Gare, France
}

\begin{abstract}
Résumé. - Pour des concentrations de $\mathrm{Ni} c<0,6$, la susceptibilité d'un atome de Ni dépend principalement du nombre de ses premiers voisins $\mathrm{Ni}$ : le nombre critique pour lequel la susceptibilité est infinie est 8 ou 9 . Ce modèle permet d'expliquer la variation de l'aimantation à saturation et de la susceptibilité non magnétique avec $c$; il implique l'existence de moments géants, et rend compte de la variation avec $c$ de la constante de Curie paramagnétique.

Abstract. - For Nickel concentration $c<0.6$, the susceptibility of a Ni atom depends mainly on the number of $\mathrm{Ni}$ nearest neighbours, the critical number for infinite susceptibility being 8 or 9 . This model accounts for the variation with $c$ of the saturation magnetization and of the non-magnetic susceptibility. It also explains the occurrence of giant moments, and the variation of the paramagnetic Curie constant with $c$.
\end{abstract}

The magnetizations of eight samples of $\mathrm{Cu}-\mathrm{Ni}$ alloys $(1 \%$ to $38 \% \mathrm{Ni}$ ) were measured in fields up to $60 \mathrm{kOe}$ at $4.2 \% \mathrm{~K}$ and $1.2 \mathrm{oK}$. The curves are interpreted as the sum of three terms : the diamagnetism of $\mathrm{Cu}$, with a negative slope $\chi_{0}$, the paramagnetism of non magnetism $\mathrm{Ni}$ atoms, with a positive slope $\chi_{\mathrm{NM}}$, and the magnetic of local moments carried by magnetic $\mathrm{Ni}$ atoms. At $1.2^{\circ} \mathrm{K}$, the high field part of the magnetization curves is linear within the experimental accuracy ; its slope is taken as $\chi_{D}+\chi_{N M}$, and its extrapolation to zero field gives the order of magnitude of the saturation magnetization $\sigma_{s}$ carried by magnetic atoms.

On figure 1 a $1 / \chi_{\mathrm{NM}}$ per Ni atoms is plotted versus

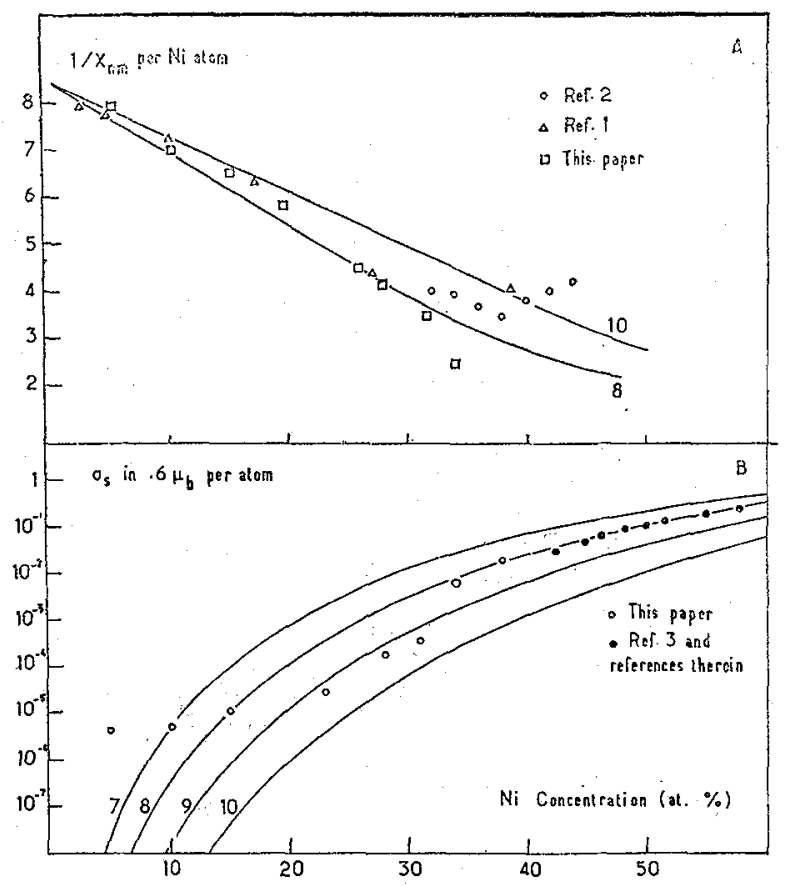

FIG, 1a, - Reciprocal susceptibilities of non-magnetic atoms compared with theoretical curves for $m=8$ and $m=10$.

b. - Mean moment per atom compared with theoretical curves for $m=7,8,9,10$.
Ni concentration, together with earlier data deduced from low field susceptibilities $[1,2]$. It can be seen that $1 / \chi_{\mathrm{NM}}$ decreases almost linearly with concentration, at least for low values of concentration. From the values of $\sigma_{\mathrm{s}}$, the mean magnetic moment per atom is derived, and shown to be non vanishing (Fig. 1b) far enough in the paramagnetic range (for lower concentrations, the values are not meaningful because of the presence of some $(\sim 10)$ p. p. mi. of $\mathrm{Fe})$.

These phenomena can be explained in the following way : Let $\rho$ be the local density of states on an isolated $\mathrm{Ni}$ atom in a copper matrix : the local susceptibility of this atom is expressed by

$$
\chi_{0} \simeq 2 \mu_{\mathrm{B}}^{2} \rho /(1-U \rho),
$$

where $U$ is the usual effective Coulomb interaction. If one $\mathrm{Ni}$ atom is nearest neighbour of this atom, the overlapping of the virtual bound states increases $\rho$ by $\Delta \rho$ and $U \rho$ by $\Delta(U \rho)$. Taking this phenomenon as additive, the local susceptibility of a $\mathrm{Ni}$ with $n \mathrm{Ni}$ nearest neighbours is given by

$$
\chi_{n}=\chi_{0}\left(1+n \frac{\Delta \rho}{\rho}\right) /\left(1-\frac{n \Delta(U \rho)}{1-U \rho}\right) .
$$

This formula can be conveniently simplified by neglecting the term $\Delta \rho / \rho$ of the first bracket, as the main effect on $\chi_{n}$ is due to the denominator. Let $m$ be the value for which this denominator vanishes. Then for $n>m, \chi_{n}$ is infinite (appearance of a local moment), and for $n<m$ the local susceptibility takes the form :

$$
\chi_{n} \simeq \chi_{0} /(1-n / m) \text {. }
$$

Taking for $P(n)$ the probability for a site to be surrounded by $p$ Ni neighbours, gives :

$$
\chi_{\mathrm{NM}}=\sum_{n<m} P(n) \chi_{n} .
$$

On figure $1 a$, theoretical curves of $1 / \chi_{\mathrm{NM}}$ per $\mathrm{Ni}$ atom are drawn for $m=8$ and 10. Clearly, the fit is good with $m=9 \pm 1$. Taking now for the appearance of a local moment a model in which the moment $\mu_{\mathrm{N} i}$ is 
either maximum or zero [3], the mean moment per site is given by :

$$
\sigma_{\mathrm{s}}=\mu_{\mathrm{Ni}} \times \sum_{p \geqslant m} P(p) .
$$

On figure $1 b$, theoretical curves of $\sigma_{\mathrm{s}}$ are drawn for $m=7,8,9,10$; it is found that $m=8$ or 9 . In a previous paper [3], it was found $m=8$. For lower concentrations, $m=9$ fits better. A qualitative explanation can be given by assuming that nearly magnetic atoms $(n=m-1)$ can be polarized by magnetic ones, like $\mathrm{Pd}$ in $\mathrm{Pd}-\mathrm{Fe}$. A rough calculation shows that their contribution to $\sigma_{\mathrm{s}}$, almost zero for $30 \% \mathrm{Ni}$, becomes important for $50 \% \mathrm{Ni}$. Then the «true » value of $m$ could be 9 , and the good fit with 8 between 40 and $60 \%$ would be due to polarization of nearly magnetic atoms.

Thus, we find that $m=9 \pm 1$ from two indepen- dent measurements, which is a test of validity of the model. It has been shown previously that this model could explain the occurrence of giant moments, by the fact that the neighbourhoods of two neighbouring atoms are not independent, which leads to a correlation of their probabilities of magnetism. Then the local «true " moments are clustered in clouds, where they are strongly magnetically coupled. Moreover, the nearly magnetic atoms in the cloud are polarized by magnetic atoms, and are also involved in the giant moment. This leads to a concentration dependent size of the giant moments, in agreement with the recent measurements of Mishra et al. [4]. With our measurements of $\sigma_{\mathrm{s}}$ and the computed values of the giant moment, the qualitative variation of the Curie constant versus $c$ has been computed. The agreement is good with the measurements of Kouvel and Comly [2].

\section{References}

[1] Pugh (E. W.), Ryan (F. M.), Phys. Rev., 1958, 111, 1038.

[2] Kouvel (J. S.), Comly (J. B.), Phys. Rev. Let., 1970, 24, 598.

[3] Perrier (J. P.), Tissier (B.), Tournier (R.), Phys. Rev. Let., 1970, 24, 313.

[4] Mishra (S.), Claus (H.), BeCK (P. A.), Phys. Let., 1970, 31A, 493. 